\title{
An Angled Stick Colonic Irrigation Device for the Bowel Management Programs in Patients with Impaired Bowel Function
}

Hiroyuki Kayaba1,3*, Hiroaki Yoshino ${ }^{2}$, Masamichi Itoga ${ }^{1,3}$, Keiya Kojima ${ }^{3}$ and Norihiro Saito ${ }^{1,3}$

${ }^{1}$ Department of Laboratory Medicine, Hirosaki University Graduate School of Medicine, Hirosaki, Japan

${ }^{2}$ Department of Pediatric Surgery, Akita University School of Medicine, Akita, Japan

${ }^{3}$ Department of Clinical Laboratory, Hirosaki University Hospital, Hirosaki, Japan

\begin{abstract}
Objective: Retrograde colonic irrigation is a treatment of choice for severe defecation disorders accompanied by congenital disorders such as anal malformations and spina bifida; however, it requires skills, effort and enough space. With the aim of making retrograde colonic irrigation easier and comfortable, we made a self-help colonic irrigation device applicable for these patients.
\end{abstract}

Methods: An angled stick colonic irrigation device was made for comfortable retrograde colonic irrigation Angulated handle colonic irrigation system was trialled by seven preschool and school age patients including four patients with spina bifida and three patients with congenital ano-rectal anomaly.

Results: Four out of seven patients operated the angulated handle colonic irrigator well. The colonic irrigation device enabled the patients with severe defecation disorders to hold the cone tip securely in place and prevented backflow and contamination.

Conclusion: The angulated handle colonic irrigator may help retrograde colonic irrigation more comfortable and easier in selected patients with spina bifida or ano-rectal malformations.

Keywords: Colonic irrigation; Constipation; Incontinence; Anorectal malformations; Spina bifida; Children; Device

\section{Introduction}

Several management options are available for the bowel management of the patients with spina bifida or congenital ano-rectal anomalies. Socially acceptable continence and prevention of fecal impaction are the goal of the bowel management. A large proportion of the patients with spina bifida have hyper-reflexic bowel and flaccid external anal sphincter, which may result in fecal incontinence [1]. A bowel evacuation on a regular schedule is satisfactory for these patients; however, it needs effort, time and good help to achieve. Glycerin enema or colonic irrigation is not successful in evacuation because the fluid runs out from the anus. Furthermore, ordinary colonic irrigation system with a cone tip requires a strong hand to secure it properly on the anus; otherwise, the hand may be contaminated by backflow. Aiming at improving bowel management of these patients, an angulated handle colonic irrigator was designed.

\section{Materials and Methods}

\section{Angulated handle colonic irrigator}

Two prototypes were made (Figure 1). Prototype I was made by hand using a polyvinyl tube. Prototype I was easy to operate, but the assembly and hygienic maintenance were difficult. Prototype II consists of three parts: the pedestal, the body and the handle. The pedestal and handle are screwed into the body of the device. The colonic irrigation set is composed of the irrigation fluid bag, the drip chamber, and the infusion tube. The infusion tube, made of polyvinyl chloride, is connected to the silicone cone through the pedestal. The cone tip is made of silicone and fixed securely on the pedestal. The system is latexfree. Because the pedestal, handle and body are separable, they can be packed in a cosmetic pouch sized bag.

\section{Colonic irrigation}

An irrigation solution was made by adding 1 gram of salt (Sodium
Chloride) to lukewarm tap water. The irrigation bag was suspended at approximately shoulder height. After lubrication, the cone tip was inserted and held securely in the anal canal by the handle. The irrigation solution was then infused until the patient feel fullness or mild abdominal discomfort. Then, the anus was unplugged by retracting the handle toward the patient. The contents were evacuated as soon as the cone was detached from the anus. The volume required for one wash differed from one patient to another.

\section{Patients}

Seven patients tested the angulated handle colonic irrigation. Four patients had spina bifida and three patients had ano-rectal malformation (Table 1). Case 1, a boy aged 8 years, had no apparent paralysis in his lower extremities. Case 2, a girl aged 18 years, could walk alone with mild weakness of the leg. The other two boys aged 12 (case 3) and 14 years old (case 4), respectively, had weakness of their lower extremities and could not walk without braces. Their ano-rectal function tests showed hyperactive rectum, loss of sensation in the perineum, and diminished sphincter function of the anus. Case 5, 6 and 7 had severe constipation since infantile period after the surgical repair for their congenital ano-rectal diseases.

*Corresponding author: Hiroyuki Kayaba, Department of Laboratory Medicine Hirosaki University Graduate School of Medicine, 5 Zaifucho, Hirosaki, 036-8562, Japan, Tel: +81-172-39-5123; Fax: +81-172-39-5306; E-mail: kayaba@cc.hirosaki-u.ac.jp

Received January 14, 2015; Accepted February 06, 2015; Published February 20, 2015

Citation: Kayaba H, Yoshino H, Itoga M, Kojima K, Saito N (2015) An Angled Stick Colonic Irrigation Device for the Bowel Management Programs in Patients with Impaired Bowel Function. J Gen Pract 3: 193. doi: 10.4172/2329-9126.1000193

Copyright: $\odot 2015 \mathrm{Kayaba} \mathrm{H}$, et al. This is an open-access article distributed under the terms of the Creative Commons Attribution License, which permits unrestricted use, distribution, and reproduction in any medium, provided the original author and source are credited. 
Citation: Kayaba H, Yoshino H, Itoga M, Kojima K, Saito N (2015) An Angled Stick Colonic Irrigation Device for the Bowel Management Programs in Patients with Impaired Bowel Function. J Gen Pract 3: 193. doi:10.4172/2329-9126.1000193

Page 2 of 3

\begin{tabular}{|c|c|c|c|c|c|c|c|c|c|c|c|}
\hline \multirow[t]{2}{*}{ No. } & \multirow[t]{2}{*}{ Age (years) } & \multirow[t]{2}{*}{ Sex } & \multirow[t]{2}{*}{ Diagnosis } & \multirow{2}{*}{\begin{tabular}{c|} 
Cord \\
Tethering \\
\end{tabular}} & \multicolumn{2}{|c|}{$\begin{array}{l}\text { Neurological } \\
\text { level (The most } \\
\text { caudal segment } \\
\text { with normal } \\
\text { function ) }\end{array}$} & \multirow[t]{2}{*}{ Brace } & \multirow[t]{2}{*}{$\begin{array}{l}\text { Use of wheel } \\
\text { chair for } \\
\text { community } \\
\text { mobility }\end{array}$} & \multirow[t]{2}{*}{$\begin{array}{l}\text { Anorectal } \\
\text { functions }\end{array}$} & \multicolumn{2}{|c|}{$\begin{array}{l}\text { Major problem in bowel } \\
\text { control }\end{array}$} \\
\hline & & & & & Sensory & Motor & & & & Incontinence & Constipation \\
\hline \multirow{2}{*}{1} & \multirow{2}{*}{8} & \multirow{2}{*}{ M } & Lumbosacral & \multirow{2}{*}{ yes } & \multirow{2}{*}{ S4-5 } & \multirow{2}{*}{$\mathrm{S} 1$} & \multirow{2}{*}{ none } & \multirow{2}{*}{ no } & Hyperactive rectum, & \multirow{2}{*}{ yes } & \multirow{2}{*}{ yes } \\
\hline & & & meningomyelocele & & & & & & Flaccid anus & & \\
\hline \multirow{2}{*}{2} & \multirow{2}{*}{12} & \multirow{2}{*}{ M } & Lumbosacral & \multirow{2}{*}{ yes } & \multirow{2}{*}{$\mathrm{S} 2$} & \multirow{2}{*}{ L3 } & \multirow{2}{*}{ ankle foot } & \multirow{2}{*}{ yes } & Hyperactive rectum, & \multirow{2}{*}{ yes } & \multirow{2}{*}{ yes } \\
\hline & & & meningomyelocele & & & & & & Flaccid anus & & \\
\hline \multirow{2}{*}{3} & \multirow{2}{*}{16} & \multirow{2}{*}{ M } & Lumbosacral & \multirow{2}{*}{ yes } & \multirow{2}{*}{ L5 } & \multirow{2}{*}{ L3 } & ankle foot & ves & Hyperactive rectum, & ves & no \\
\hline & & & meningomyelocele & & & & dirkte tout & yes & Flaccid anus & yes & 110 \\
\hline 4 & 18 & $\mathrm{~F}$ & Lumbosacral & ves & $\$ 3$ & 4 & none & no & Hyperactive rectum, & ves & $\mathrm{no}$ \\
\hline 4 & 10 & $r$ & meningomyelocele & yes & 00 & L4 & mome & 110 & Flaccid anus & yes & 110 \\
\hline 5 & 9 & M & $\begin{array}{l}\text { Anal agenesis } \\
\text { (post-anoplasty) }\end{array}$ & no & - & - & - & no & $\begin{array}{c}\text { Nointernal anal } \\
\text { sphincteric activity } \\
\text { on manometric } \\
\text { study }\end{array}$ & yes & yes \\
\hline 6 & 5 & M & $\begin{array}{l}\text { Rectourethral fistula } \\
\text { (post-anoplasty) }\end{array}$ & no & - & - & - & no & $\begin{array}{l}\text { Diminished internal } \\
\text { anal shincteric } \\
\text { activity on } \\
\text { manometric study, }\end{array}$ & yes & yes \\
\hline & & & & & & & & & tight anal canal & & \\
\hline & & & $\begin{array}{l}\text { Hirschsprung's } \\
\text { disease }\end{array}$ & & & & & & & & \\
\hline 7 & 15 & $\mathrm{~F}$ & $\begin{array}{l}\text { (Treated with } \\
\text { modified Duhamel's } \\
\text { procedure) }\end{array}$ & no & - & - & - & no & No rectoanal reflex & no & yes \\
\hline
\end{tabular}

Table 1: Clinical characteristics of the patients who tried the angulated handle colonic irrigator. Ethical aspects.

\section{A}

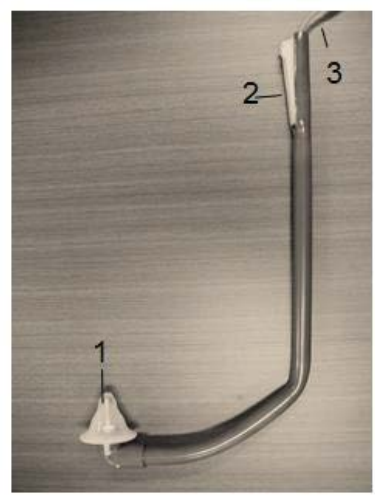

B
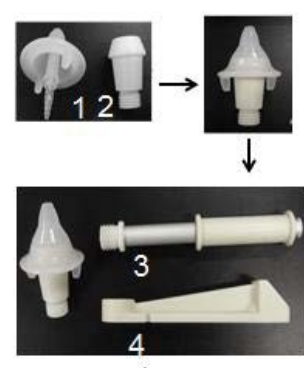

$\downarrow$

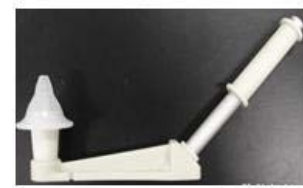

Figure 1: Angulated handle colonic irrigator prototypes. Panel A: Schematic drawing of the angulated handle colonic irrigator prototype $\mathrm{I}$. The lateral view of the angulated handle colonic irrigator is shown. A silicon cone tip (1) and water clamp (2) is attached to the handle. A vinyl tube (3) connecting the silicon cone and irrigation bag runs inside the handle. The prototype I was easy to operate but not the assembly and hygienic maintenance. Panel B: Assembly drawing of the angulated handle colonic irrigator prototype II. Silicone tip (1) is fixed to the pedestal (2) securely. Then, the pedestal and handle (3) are screwed into the body (4). A colonic irrigation set composed of a water clamp and irrigation bag could be connected to the silicone tip through the pedestal. The portability, assembly and hygienic maintenance were improved in the prototype II.

The patients and their parents need to be well-informed about the study. The procedures of the colonic irrigation were conducted after obtaining informed consent from the patients and their parents. The study was approved by the Ethics Committee of Akita University Graduate School of Medicine (Approval No 334) and Hirosaki University Graduate School of Medicine (Approval No 2013-113).

\section{Results}

The total amount of irrigation solution and time required for one course of irrigation ranged from 1 to 6 litters and 15 to 60 minutes, respectively. With the aid of the principles of lever (Figure 2), backflow could be prevented if the cone tip was fixed securely in the appropriate position during infusion. Case 1 and 2 could adjust the position of the cone tip appropriately. A boy aged 16 years could not fix the cone tip because of the obesity and poor control of the body position. A girl, aged 18 years suffering from accidental incontinence in daily life, could operate the device, but she preferred manual extraction and sanitary napkins to colonic irrigation. Case 5, 6 and 7 had no difficulty in the operation of the device. Case 6 and 7 had improvement in their bowel control, but case five preferred colonic irrigation by his parents to the angulated handle irrigator.

\section{Discussion}

Since bowel dysfunction is a major source of morbidity in individuals with spina bifida and congenital anal malformations, good bowel management is essential in their daily life [1,2]. The bowel management is a time burden for their family too [3]. Retrograde colonic enema is a common choice for bowel management in the patients with spina bifida [4,5]. Accentuated recto-anal reflex and paralytic external anal sphincter cause fecal incontinences. The hyperactivity of the rectum1, prolonged recto-anal inhibitory reflex [6], decreased anal resting pressure [7], and diminished rectal sensation [8] are reported in spina bifida. Because the patients with congenital anal malformations have under-developed anatomical structures required for bowel controls, bowel management is a long and hard work for these patients. As it was shown in this study, the angulated handle colonic irrigator was applicable for limited number of patients. The patients accompanying severe motor dysfunction of the trunk and lower extremities could not keep their position on the commode. Furthermore, extensive loss of sensation beyond perianal region makes the patients hard to find 


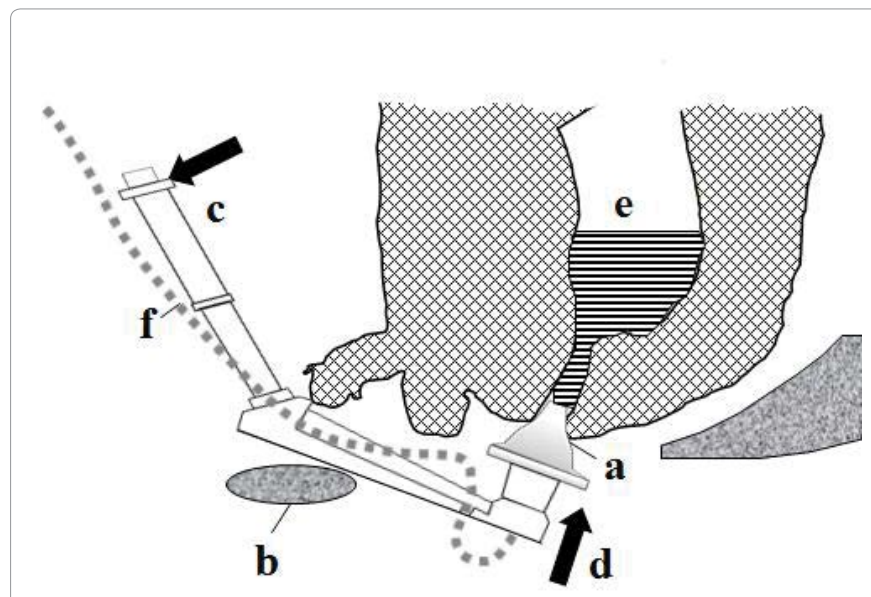

Figure 2: Schematic drawing of retrograde colonic irrigation using the angulated handle colonic irrigator. First, the cone tip (a) is placed on the anus, and the angular portion of the handle is on the anterior edge of toilet seat (b) Next, the tail of the handle is pushed forward (c) to fix the cone tip securely in the anal canal. After that, irrigation fluid can be infused into the rectum (e) through irrigation circuit (f) without backflow. When the patient feels abdominal discomfort or urge to defecate, the angulated handle is pulled to release the cone tip from the anus. At the release of the cone tip, the irrigation fluid and colonic content are evacuated into the commode. The volume of the irrigation fluid for one wash ranges from $200-500 \mathrm{ml}$.

the anus by themselves. As a result, only the patients of spina bifida with a limited loss of motor and sensational functions could handle the irrigator. The patients treated for ano-rectal anomalies, on the other hand, had no motor and sensational loss in their lower half of the body, and could use the irrigator well. The angulated handle colonic irrigator could help only the selected patients; however, it required less effort, help and time than a simple cone tip. This device could widen the choice for bowel management techniques in patients with spina bifida and congenital ano-rectal diseases; however, not every patient may accept this system.

\section{Conclusion}

The stick colonic irrigator was applicable only to selected cases. Nonetheless, the stick colonic irrigator may facilitate in some of the patients with congenital diseases such as spina bifida and ano-rectal malformations to learn bowel managements by themselves.

\section{Acknowledgement}

The authors declare that they have no conflicts of interest in the research This work was supported by Japan Science and Technology Agency grant AS232Z02123F

\section{References}

1. Kayaba H, Hebiguchi T, Itoh Y, Yoshino H, Mizuno M, et al. (2003) Evaluation of anorectal function in patients with tethered cord syndrome: saline enema test and fecoflowmetry. J Neurosurg 98: 251-257.

2. Verhoef M, Lurvink M, Barf HA, Post MW, van Asbeck FW, et al. (2005) High prevalence of incontinence among young adults with spina bifida: description, prediction and problem perception. Spinal Cord 43: 331-340.

3. Stellman GR, Gilmore M, Bannister CM (1983) A survey of the problems of bowel management experienced by families of spina bifida children. $Z$ Kinderchir 38 Suppl 2: 96-97.

4. Schöller-Gyüre M, Nesselaar C, van Wieringen H, van Gool JD (1996) Treatment of defecation disorders by colonic enemas in children with spina bifida. Eur J Pediatr Surg 6 Suppl 1: 32-34.

5. Shandling B, Gilmour RF (1987) The enema continence catheter in spina bifida: successful bowel management. J Pediatr Surg 22: 271-273.

6. Kayaba H, Sakamoto T, Kodama K (1994) Evaluation of manometric findings and ability to defecate in patients with menigocele and meningomyelocole. $J$ Jpn Soc Coloproctol 48: 438-445.

7. Arhan P, Faverdin C, Devroede G, Pierre-Kahn A, Scott H, et al. (1984) Anorectal motility after surgery for spina bifida. Dis Colon Rectum 27: 159-163.

8. Agnarsson U, Warde C, McCarthy G, Clayden GS, Evans N (1993) Anorecta function of children with neurological problems. I: Spina bifida Dev Med Child Neurol 35: 893-902. 